\title{
Strategi Pengembangan Agroindustri Kopi di Kabupaten Kerinci
}

\section{(Strategy for the Development of Coffee Agroindustry in Kerinci Regency)}

\author{
Dina Yuliasty Lamefa ${ }^{1)^{*}}$, Sukardi ${ }^{2)}$, Sapta Raharja ${ }^{2)}$ \\ ${ }^{1)}$ Program Studi Teknologi Industri Pertanian, Sekolah Pascasarjana Institut Pertanian Bogor, \\ Gedung Fateta Lt.2 Jl. Lingkar Akademik Kampus IPB, Babakan, Kec. Dramaga, Bogor, Jawa \\ Barat 16680, Indonesia, dan ${ }^{2)}$ Departemen Teknologi Industri Pertanian, Fakultas Teknologi \\ Pertanian, Gedung Fateta Lt.2 Jl. Lingkar Akademik Kampus IPB, Babakan, Kec. Dramaga, \\ Bogor, Jawa Barat 16680, Indonesia \\ E-mail: dinalamefa09@gmail.com
}

\begin{abstract}
Coffee is one of the plantation products with significant importance in the economy of Kerinci Regency, and several obstacles have been reported in agroindustry development. This study is focused on designing a strategy to develop the industry in the region. The study was conducted in Kerinci Regency from January 2017 until October 2017. The data was collected by observation, questionnaires, and in-depth interviews through Focus Group Discussion (FGD). In addition, research analysis used internal and external factor methods, internal and external matrices (IE Matrix), and SWOT matrices. The result show the value of the internal and external factors obtained to be 2,759 and 2,888, respectively. When mapped, the IE matrix value is in cell V (five). However, the suitable strategies are the growth and stability strategy, essential for market penetration and product development. Based on AHP analysis, the three main strategic priorities to be applied are land expansion $(0,230)$, guidance and facilitation of the market information $(0,178)$, and infrastructure improvement $(0,124)$.
\end{abstract}

Keywords: agroindustry, agribusiness, AHP analysis, Strategy, SWOT

DOI: http://dx.doi.org/10.25181/jaip.v8i2.1480

Diterima: 28 Desember 2019 / Disetujui: 11 Agustus 2020 / Diterbitkan: 15 Oktober 2020

\section{PENDAHULUAN}

Indonesia adalah negara penghasil kopi keempat terbesar di dunia setelah Brazil, Vietnam, dan kolombia. Jumlah produksi kopi Indonesia tahun 2018 sebanyak 612.000 ton. Brazil merupakan negara tertinggi yang memproduksi kopi sebanyak 3.750.000 ton, Vietnam sebanyak 1.800.000 ton. Kolumbia sebanyak 837.000 ton dan negara kelima terbesar memproduksi kopi yaitu negara Ethiopia sebanyak 450.000 ton (ICO, 2019).

Sektor pertanian mempunyai keterkaitan yang erat dengan sektor-sektor lain. Perkembangan sektor-sektor lain sangat tergantung pada produk-produk sektor pertanian bukan saja sebagai kelangsungan suplai makanan yang mengikuti pertumbuhan penduduk tetapi juga 
sebagai penyediaan bahan baku yang digunakan sektor industri. Sektor pertanian juga merupakan suatu sumber modal untuk investasi ekonomi wilayah melalui transfer surplus kapital dari sektor pertanian ke sektor-sektor ekonomi lain, antara lain peran cukup besar yaitu sektor perkebunan kopi (Suandi 2014). Kopi merupakan salah satu komoditas andalan dalam sektor perkebunan Indonesia. Peran komoditas kopi bagi perekonomian Indonesia cukup penting, baik sebagai sumber pendapatan bagi petani kopi, sumber devisa, penghasil bahan baku industri, maupun penyedia lapangan kerja melalui kegiatan pengolahan, pemasaran, dan perdagangan seperti ekspor dan impor (Chandra et al., 2013).

Data statistik dari International Coffee Organization (ICO) konsumsi kopi dunia pada tahun 2018 hingga 2019 naik 2,1\% menjadi 164,77 juta kantong. Konsumsi kopi di Asia \& Oseania diperkirakan naik 3,7\% menjadi 35.325 kantong sementara konsumsi Afrika akan meningkat 3\% menjadi 11.880 kantong. Permintaan di kedua wilayah ini tumbuh lebih cepat daripada negaranegara lainnya. Permintaan di Amerika Utara diperkirakan tumbuh sebesar 2,2\% menjadi 29.941 kantong, di Eropa sebesar 1,5\% menjadi 52.999 kantong dan di Amerika Selatan sebesar 1,1\% menjadi 26.964 kantong. Konsumsi Meksiko \& Amerika Tengah diperkirakan 0,2\% lebih tinggi pada 5.257 kantong (ICO, 2019). Konsumsi kopi Indonesia tahun 2018 hingga 2019 mencapai 4.700 kantong. Seiring dengan meningkatnya gaya hidup minum kopi di Indonesia pada tahun 2019 hingga 2020 konsumsi kopi Indonesia diperkirakan naik menjadi 4.900 sampai 5.500 kantong (GAIN, 2019).

Kopi merupakan salah satu komoditas perkebunan andalan Kabupaten Kerinci. Kabupaten Kerinci terletak di Provinsi Jambi dengan ketinggan wilayah 500 - 1.500 mdpl sehingga sangat cocok ditanami kopi jenis Robusta dan Arabika. Produksi dua jenis kopi ini terdapat di Kecamatan Gunung Raya, Batang Merangin, Keliling Danau, Danau Kerinci, Sitinjau Laut, Air Hangat, Air Hangat timur, Depati VII, Gunung Kerinci, Siulak, Kayu Aro dan Gunung Tujuh. Data Dinas Perkebunan dan Peternakan (2018) menunjukkan bahwa pada tahun 2017 luas tanaman perkebunan kopi robusta di Kabupaten Kerinci sebanyak 6.914 ha, dengan produksi 3.894 ton dan luas tanaman perkebunan kopi arabika 1.809 ha dengan produksi 171 ton. Kabupaten Kerinci merupakan salah satu daerah yang saat ini gencar membudidayakan tanaman kopi. Jumlah permintaan kopi baik di pasar domestik maupun ekspor terutama kopi jenis green bean di Kabupaten Kerinci pada tahun 2018 mencapai lebih dari 10 ribu ton.tahun ${ }^{-1}$, namun jumlah permintaan yang dapat dipenuhi hanya sekitar 2.440 ton.tahun $^{-1}$ sehingga hanya dapat memenuhi $24 \%$ dari jumlah permintaan pasar.

Berdasarkan laporan dari Dinas Perkebunan dan Peternakan Kabupaten Kerinci (2018), permasalahan yang dihadapi oleh petani kopi adalah belum didukung dengan pengolahan pasca panen yang tepat, sehingga sangat mempengaruhi harga yang akan diterima oleh petani dan produk olahan yang dihasilkan terbatas. Saat ini pengolahan kopi di Kabupaten Kerinci hanya sebatas menghasilkan biji kopi beras atau sering disebut dengan green bean yang kemudian dijual atau diekspor, hanya sedikit yang sampai pada tahap pengolahan dan pengemasan padahal permintaan 
produk olahan kopi juga tinggi seiring meningkatnya konsumsi minuman kopi di masyarakat. Petani kopi Kabupaten Kerinci sejauh ini belum mampu memasarkan secara optimal. Hal ini disebabkan karena munculnya berbagai kendala internal dan eksternal yang menghambat dalam proses pengolahan maupun pemasaran kopi secara langsung maupun tidak langsung. Kendala yang muncul antara lain seperti wilayah pemasaran produk kopi yang sebagian besar masih berskala lokal, proses penanganan kopi dari panen sampai pascapanen masih secara konvensional, penanganan produk kopi kurang efektif baik dari segi pengolahan, pengemasan dan penyimpanan, permodalan minim, harga kopi yang fluktuatif, dan munculnya pesaing dengan produk sejenis dari daerah lain. Sarana dan prasarana sangat penting dalam menunjang perekonomian suatu daerah. Perbedaan pola spasial luas lahan, tenaga kerja, produksi dan modal petani juga sangat penting. Jika hal tersebut dapat optimal, maka dapat memaksimumkan profit yang lebih besar untuk daerah tersebut (Abdullah, 2017).

Mengingat komoditas kopi memegang peranan penting dalam perekonomian Kabupaten Kerinci, maka perlu dilakukan upaya untuk mengembangkan agribisnis dan agroindustri kopi. Oleh sebab itu, penelitian ini dilakukan untuk mengidentifikasi berbagai faktor strategis internal dan eksternal yang menjadi pendukung dan penghambat dalam pengembangan agroindustri kopi di kabupaten kerinci, memformulasikan strategi pengembangan industri kopi untuk mengatasi masalah tersebut serta menentukan strategi prioritas pengembangan agroindustri kopi di Kabupaten Kerinci.

\section{METODE PENELITIAN}

Penelitian ini dilakukan di Kabupaten Kerinci mulai Januari 2017 sampai dengan Oktober 2017. Penelitian menggunakan dua jenis data, yaitu data primer dan data sekunder. Data primer diperoleh melalui observasi, wawancara dan pengisian kuisioner kepada responden yang berasal dari instansi pemerintah daerah kabupaten kerinci, pakar dari perguruan tinggi, petani kopi, pedagang pengumpul biji kopi serta masyarakat umum yang akan menjadi calon konsumen dari produk kopi. Data sekunder didapatkan dari buku-buku, publikasi dari instansi pemerintah (Badan Pusat Statistik, Dinas Perkebunan dan Peternakan, Dinas Koperasi, Perindustrian dan Perdagangan), jurnal nasional maupun jurnal internasional, laporan penelitian yang terkait dengan strategi pengembangan agroindustri serta dokumen-dokumen lain yang relevan.

Strategi pengembangan agroindustri kopi di kabupaten Kerinci menggunakan analisis SWOT (strengths, weaknesse, opportunities, threats) dengan mendalami faktor internal (kekuatan dan kelemahan) dan faktor eksternal (peluang dan ancaman). Dalam tahap input ini dilakukan pembobotan setiap variabel menggunakan metode pairwise comparison, penentuan peringkat dan membentuk matriks Internal Factor Evaluation (IFE) dan External Factor Evaluation (EFE). Tahap berikutnya adalah tahap pemaduan (Matching Stage) dengan 
menggunakan matriks internal dan eksternal (IE) dilanjutkan dengan matriks SWOT (Rangkuti, 2016). Alternatif strategi yang dihasilkan untuk pengembangan agroindustri kemudian dilakukan penetapan strategi pilihan dengan metode Analytical Hierarchy Process (AHP) (Saaty, 1993).

Penilaian bobot pada kuesioner Analytical Hierarchy Process (AHP) yang telah diisi oleh para pakar selanjutnya dinilai menggunakan program komputer Expert Choice. Penilaian juga dapat dihitung dengan cara manual. Menurut Tominanto (2012) langkah pertama metode AHP adalah penyusunan hirarki dengan menentukan tujuan yang merupakan sasaran sistem secara keseluruhan pada level teratas. Level berikutnya terdiri dari kriteria-kriteria untuk menilai atau mempertimbangkan alternatif-alternatif yang ada dan menentukan alternatif-alternatif tersebut. Setiap kriteria dapat memiliki subkriteria di bawahnya dan setiap kriteria dapat memiliki nilai intensitas masing-masing.

Penilaian dari setiap kuisioner yang diisi oleh beberapa pakar digabungkan. Penilaian dari beberapa pakar digabungkan dengan menggunakan persamaan rata-rata geometri seperti persamaan

$$
\mathrm{GM}=\sqrt[n]{(X 1)(X 2) \ldots(X n)}
$$

Dimana :

$\begin{array}{ll}\mathrm{GM} & =\text { Geomertic Mean } \\ \mathrm{X}_{1} & =\text { Pakar ke-1 } \\ \mathrm{X}_{2} & =\text { Pakar ke-2 } \\ \mathrm{Xn} & =\text { Pakar ke- } \mathrm{n}\end{array}$

Penyusunan matrik perbandingan berpasangan dilakukan untuk menentukan prioritas elemen yaitu dengan cara membandingkan elemen secara berpasangan sesuai dengan kriteria yang diberikan dengan menggunakan bentuk materiks. Susunan matrik perbandingan berpasangan dapat dilihat pada Tabel 1.

Tabel 1. Susunan matrik perbandingan berpasangan

\begin{tabular}{ccccc}
\hline Kriteria/alternatif & 1 & 2 & 3 & $\mathrm{n}$ \\
\hline 1 & 1 & $\mathrm{GM} 12$ & $\mathrm{GM} 13$ & $\mathrm{GM} 1 \mathrm{n}$ \\
2 & $\mathrm{GM} 21$ & 1 & $\mathrm{GM} 23$ & $\mathrm{GM} 2 \mathrm{n}$ \\
3 & $\mathrm{GM} 31$ & $\mathrm{GM} 32$ & 1 & $\mathrm{GM} 3 \mathrm{n}$ \\
$\mathrm{n}$ & $\mathrm{GMn} 1$ & $\mathrm{GMn} 2$ & $\mathrm{GMn} 3$ & 1 \\
\hline
\end{tabular}

Matrik perbandingan berpasangan diisi dengan menggunakan bilangan untuk merepresentasikan kepentingan relatif dari satu elemen terhadap elemen lainnya yang dimaksud dalam bentuk skala 1 sampai 9. Skala ini mendefenisikan dan menjelaskan nilai 1 sampai 9 untuk pertimbangan dalam perbandingan berpasangan elemen pada setiap level hirarki terhadap suatu kriteria di level yang lebih tinggi. Apabila suatu elemen dalam matrik dibandingkan dengan elemennya sendiri, maka diberi nilai 1 . Jika $\mathrm{i}$ dibanding $\mathrm{j}$ mendapatkan nilai tertentu, maka $\mathrm{j}$ dibanding i merupakan kebalikannya. 
Pertimbangan-pertimbangan terhadap perbandingan berpasangan disintesis untuk memperoleh keseluruhan prioritas yaitu dengan cara menjumlahkan nilai-nilai dari setiap kolom pada matriks, membagi setiap nilai dari kolom dengan total kolom yang bersangkutan untuk memperoleh normalisasi matrik, menjumlahkan nilai dari setiap matrikdan membaginya dengan jumlah elemen untuk mendapatkan nilai rata-rata, dan mengukur konsistensi.

Pengukuran konsistensi penting dilakukan untuk mendapatkan hasil yang valid dalam dunia nyata. Nilai konsistensi rasio harus kurang dari $5 \%$ untuk matrik $3 \times 3,9 \%$ untuk matrik $4 \times 4$ dan $10 \%$ untuk matrik yang lebih besar. Nilai konsistensi dihitung dengan mengalikan nilai pada kolom pertama dengan prioritas relatif elemen pertama, nilai pada kolom kedua dengan prioritas relatif elemen kedua, dan seterusnya. Menjumlahkan setiap baris, hasil dari penjumlahan baris dibagikan dengan elemen prioritas relatif yang bersangkutan, hasilnya dibagi dengan banyak elemen yang ada hasilnya disebut eigen value ( $\lambda$ mksimum). Indeks konsistensi (consistency index) dihitung seperti pada persamaan 2 .

$$
C I=\frac{\lambda \text { maksimum }-n}{n-1}
$$

Dimana :

$$
\begin{array}{ll}
\mathrm{CI} & =\text { Indeks konsistensi } \\
\lambda \text { maksimum } & =\text { Eigen value } \\
\mathrm{n} & =\text { Banyak elemen }
\end{array}
$$

Pengambilan keputusan dengan menggunakan AHP, Saaty (2001) mendefenisikan sebuah rasio konsistensi (CR) sebagai penilaian toleransi kriteria matrik yang konsisten. Rumus rasio konsistensi (CR) dapat ditemukan pada persamaan 3.

$$
C R=\frac{C I}{R C}
$$

Dimana :

$\mathrm{CR}=$ Ratio consistency

$\mathrm{CI}=$ Consistency index

$\mathrm{RC} \quad=$ Random consistency

Apabila nilai CR matrik lebih kecil dari $10 \%(0,1)$ berarti menunjukkan nilai ketidak konsistenan pendapat masing-masing pakar dianggap dapat diterima.

\section{HASIL DAN PEMBAHASAN}

\section{Analisis Matriks IE}

Berdasarkan hasil penelitian diperoleh nilai faktor internal sebesar 2,759 dan nilai faktor eksternal sebesar 2,888. Jika dipetakan pada matriks IE maka nilai tersebut berada pada sel V (lima). Strategi yang sesuai untuk pengembangan agroindustri kopi di Kabupaten Kerinci adalah 
strategi pertumbuhan (growth) dan strategi stabilitas (stability) strategi tersebut berupa penetrasi pasar dan pengembangan produk (Gambar 1).

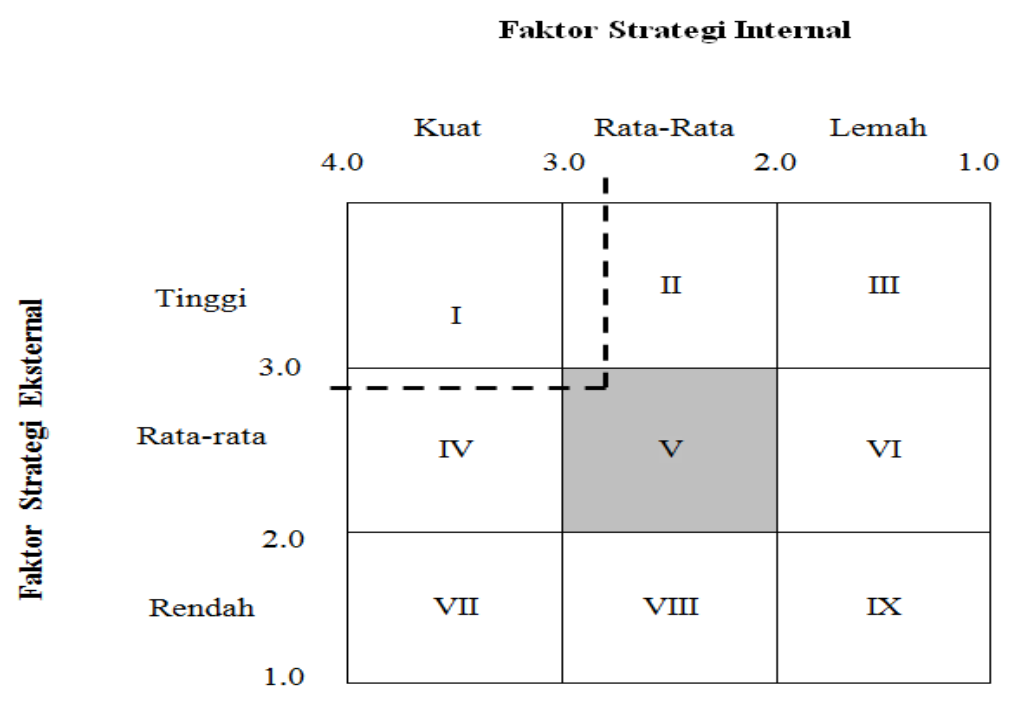

Gambar 1. Matriks IE

Berdasarkan gambaran dari matriks IE diatas, maka kondisi agroindustri kopi di Kabupaten Kerinci perlu diarahkan menuju peningkatan produk dan penetrasi pasar. Menurut David (2009) penetrasi pasar (market penetration) adalah strategi yang mengusahakan peningkatan pangsa pasar untuk produk atau jasa yang ada di pasar saat ini melalui upaya-upaya pemasaran yang lebih besar. Selain itu, pengembangan teknologi pengolahan juga harus dilakukan secara intensif untuk menghasilkan produk yang dapat memiliki kualitas ekspor. Jika kedua tersebut sudah dijalankan bukan tidak mungkin terbuka pasar yang lebih luas untuk produk kopi di Kabupaten Kerinci dan pengembangan agroindustri dapat berjalan lebih baik.

\section{Analisis SWOT}

Strategi yang dapat dilakukan dalam pengembangan agroindustri kopi di Kabupaten Kerinci dengan mengombinasikan kekuatan dan peluang dalam meminimumkan kelemahan dan menghadapi ancaman adalah sebagai berikut:

\section{Strategi SO (Strength - Opportunity)}

\section{Perluasan lahan}

Perluasan lahan dilakukan untuk meningkatkan produksi kopi Kerinci, khususnya untuk kopi arabika. Kabupaten Kerinci berada pada ketinggian 500 - 1.500 mdpl sehingga cocok untuk tanaman kopi arabika yang hanya sesuai ditanam pada lahan dataran tinggi yaitu $1.000-1.500$ mdpl. Lahan yang dimanfaatkan untuk lahan perkebunan dan pertanian di Kabupaten Kerinci sebanyak 49\% dari total keseluruhan luas wilayah. Sedangkan sebagian besar penduduk bekerja di 
bidang perkebunan dan pertanian sehingga dukungan pemerintah untuk perluasan lahan perlu dilakukan dengan memanfaatkan lahan yang tertinggal dan lahan di lereng-lereng gunung yang selama ini tidak pernah dimanfaatkan.

\section{Penerapan sertifikasi}

Penerapan sertifikasi pada produk kopi diharapkan dapat meningkatkan kualitas, produktivitas kopi dan pendapatan petani. Sertifikasi mengarahkan petani kopi pada sistem penanaman, budidaya, penanganan pascapanen yang baik dan berkelanjutan sesuai standar yang telah ditetapkan oleh setiap lebaga sertifikasi yang mengutamakan aspek lingkungan dan sosial. Ada beberapa jenis sertifikasi yang digunakan adalah sertifikasi Organic, Fair Trade, Bird Friendly, Rainforest, Indikasi Geografis (IG), C.A.F.E Practices dan lain sebagainya. Menurut Hanggar et al. (2017) yang melakukan penelitian manfaat sertifikasi kopi di Nicaragua menyatakan bahwa usahatani kopi yang bersertifikasi memiliki produktivitas dan pendapatan yang lebih tinggi dibandingkan dengan non sertifikasi karena harga rata-rata yang diterima oleh petani untuk kopinya secara signifikan dipengaruhi oleh sertifikasi.

\section{Pembentukan Science Techno Park (STP)}

Science Techno Park (STP) merupakana kawasan yang dikelola secara profesional dengan tujuan meningkatkan kesejahteraan dan perekonomian suatu daerah. Pembentukan Science Techno Park (STP) kopi perlu dibangun untuk membantu pengembangan agroindustri kopi di Kabupaten Kerinci untuk pengembangan inovasi baru dalam kawasan terpadu dengan tujuan meningkatkan keunggulan daerah. Hal ini sejalan dengan program pemerintah pusat dalam Rencana Pembangunan Jangka Menengah Nasional (RPJMN) tahun 2015-2019 menetapkan salah satu sasarannya adalah terbangunnya 100 techno park di daerah kabupaten/kota dan science park di setiap provinsi (Tolinggi \& Gubali, 2018).

\section{Strategi WO (Weakness - Opportunity)}

Bantuan bagi industri kopi (green bean \& bubuk kopi) berupa pemberian mesin dan peralatan pengolahan kopi

Perlu adanya dukungan dan kebijakan dari pemerintah terhadap pelaku industri kopi berupa mesin dan peralatan pengolahan kopi untuk mengatasi masalah fasilitas operasi dan teknologi pengolahan. Dari wawancara dengan pelaku industri salah satu kendala dalam pengolahan kopi adalah minimnya kapasitas lantai jemur kopi yang dimiliki oleh pelaku industri.

\section{Pembinaan dan fasilitasi informasi pasar komoditas kopi}

Informasi pasar atau harga bagi petani selama ini diperoleh dari sesama petani dan dari pedagang. Harga menjadi acuan seberapa besar nilai pada produk yang dihasilkan oleh petani. Petani harus mempertimbangkan seberapa besar harga yang pantas untuk produk yang dihasilkan, 
dari biaya-biaya yang dikeluarkan dari proses produksi hingga produk sampai ke lembaga pemasaran selanjutnya. Petani harus bisa membaca kondisi harga ketika menentukan harga produk di pasar saat produknya akan dijual. Menurut Sitanggang et a.l (2013) pada kawasan agroindustri perlu dikembangkan Klinik Konsultasi Agribisnis (KKA) yang berfungsi sebagai sumber informasi (modal, pasar, tehnologi dan pelatihan) bagi petani sekitarnya. Kegiatan ini sebaiknya merupakan kegiatan kerjasama lembaga penelitian, lembaga penyuluhan, masyarakat dan atau swasta

\section{Strategi ST (Strength - Threat)}

\section{Memanfaatkan sertifikat IG untuk menarik mitra usaha dan mengoptimalkan potensi pasar}

Indikasi Geografis (IG) merupakan sebuah tanda yang digunakan sebagai penunjuk daerah asal suatu barang atau produk yang karena faktor lingkungan geografis berupa faktor alam, faktor manusia atau keduanya menghasilkan reputasi, kualitas, dan karakteristik tertentu pada barang atau produk yang dihasilkan. Kopi kerinci sudah memiliki sertifikat Indikasi Geografis (IG) pada tahun 2017 yang mana sertifikat IG ini dapat dimanfaatkan untuk menarik mitra usaha dan memperluas peluang pasar internasional.

\section{Melakukan promosi kopi Kerinci}

Untuk meningkatkan nilai penjualan perlu adanya promosi sebagai salah satu strategi pemasaran kopi, Promosi dapat dilakukan melalui media cetak, elektronik ataupun festival kopi kerinci dengan menekankan keunggulan kopi kerinci dengan kopi pesaing dari daerah lain, contohnya kopi kerinci mempunyai cita rasa yang khas (Fruity, aftertaste yang manis, aroma rempah kayu manis, dan sebagainya) sehingga kopi kerinci mempunyai ciri khas tersendiri di masyarakat. Mojo et al. (2016) menyatakan bahwa keberadaan kelembagaan dalam mengelola pemasaran sampai pada taraf promosi sangat penting dalam meningkatkan kesejahteraan petani dan industri.

\section{Strategi WT (Weakness - Threat)}

\section{Memperbaiki kemasan (packaging) kopi yang masih sederhana}

Pengemasan merupakan salah satu sarana untuk menciptakan produk inovatif bervariatif. Hal ini sangat penting dan mutlak diperlukan dalam persaingan dunia usaha seperti saat ini. Kemasan merupakan faktor yang sangat penting karena fungsi dan kegunaanya dalam meningkatkan mutu produk dan daya jual dari produk. Kemasan produk dan labelnya selain berfungsi sebagaipengaman produk yang terdapat di dalamnya juga berfungsi sebagai media promosi dan informasi dan produk yang bersangkutan. Kemasan produk yang baik dan menarik akan memberikan nilai tersendiri sebagai daya tarik bagi konsumen. Kemasan produk masih merupakan masalah bagi para pelaku industri kopi, khususnya usaha kecil menengah. Permasalahan tentang kemasan produk dan labelnya kadang-kadang menjadi hambatan bagi perkembangan atau kemajuan suatu usaha (Syarif \& Halid, 1993). 


\section{Diversifikasi dan inovasi produk olahan berbasis kopi}

Menurut Sudjarmoko (2013) salah satu permasalahan dalam perkembangan agroindustri kopi di Indonesia adalah kurangnya kemampuan melakukan inovasi dan diversifikasi produk olahan kopi. Oleh sebab itu perlu adanya upaya pengembangan produk turunan olahan kopi tidak hanya bahan mentah (green bean) agar dapat meningkatkan nilai tambah kopi seperti parfum kopi, bahan kosmetik, herbal, farmasi, essen makanan dan sebagainya sesuai dengan permintaan pasar domestik maupun internasional.

\section{Perbaikan infrastruktur}

Infrastruktur merupakan salah satu faktor penentu keberhasilan pengembangan agroindustri kopi. Sarana dan prasarana fisik tersebut meliputi sarana dan prasarana budidaya kopi, sarana dan prasarana penyimpanan dan pengangkutan, transportasi (jalan) dan telekomunikasi (Nalurita et al., 2014). Lahan perkebunan kopi arabika dan robusta kerinci sebagian besar terletak di daerah perbukitan, khusus untuk kopi arabika yang menuntut lingkungan dengan suhu rendah dan umumnya terdapat di dataran tinggi, belum di dukung oleh sarana infrastruktur yang memadai. Terutama kondisi jalan yang buruk dan jarak yang jauh dari kebun kopi menuju pasar. Hal ini akan berpengaruh pada hal distribusi produk, yang akan meningkatkan biaya transportasi yang merupakan harga input, tidak sejalan dengan harga output yang rendah. Oleh karena itu, perlu dilakukan perbaikan infrastruktur pada lahan budidaya tanaman kopi dengan cara pengerasan dan pengaspalan jalan sehingga transportasi menuju lahan maupun dalam distribusi pengiriman produk kopi dapat berjalan dengan baik dan dapat mengoptimalkan harga kopi.

\section{Analisis Pemilihan Alternatif Strategi}

Berdasarkan studi literatur, wawancara dan pengisian kuesioner yang dilakukan kepada beberapa responden, diperoleh suatu hirarki strategi pengembangan agroindustri kopi di Kabupaten Kerinci yang terbagi menjadi 5 level yaitu goal, faktor, aktor, tujuan dan alternatif strategi. Hierarki strategi pengembangan agroindustri kopi di Kabupaten Kerinci sebagaimana tercantum pada Gambar 2, merupakan acuan yang digunakan dalam penentuan prioritas strategi melalui matriks perbandingan berpasangan. Nilai skor yang diperoleh diolah dengan menggunakan Software Expert Choice 11 . 


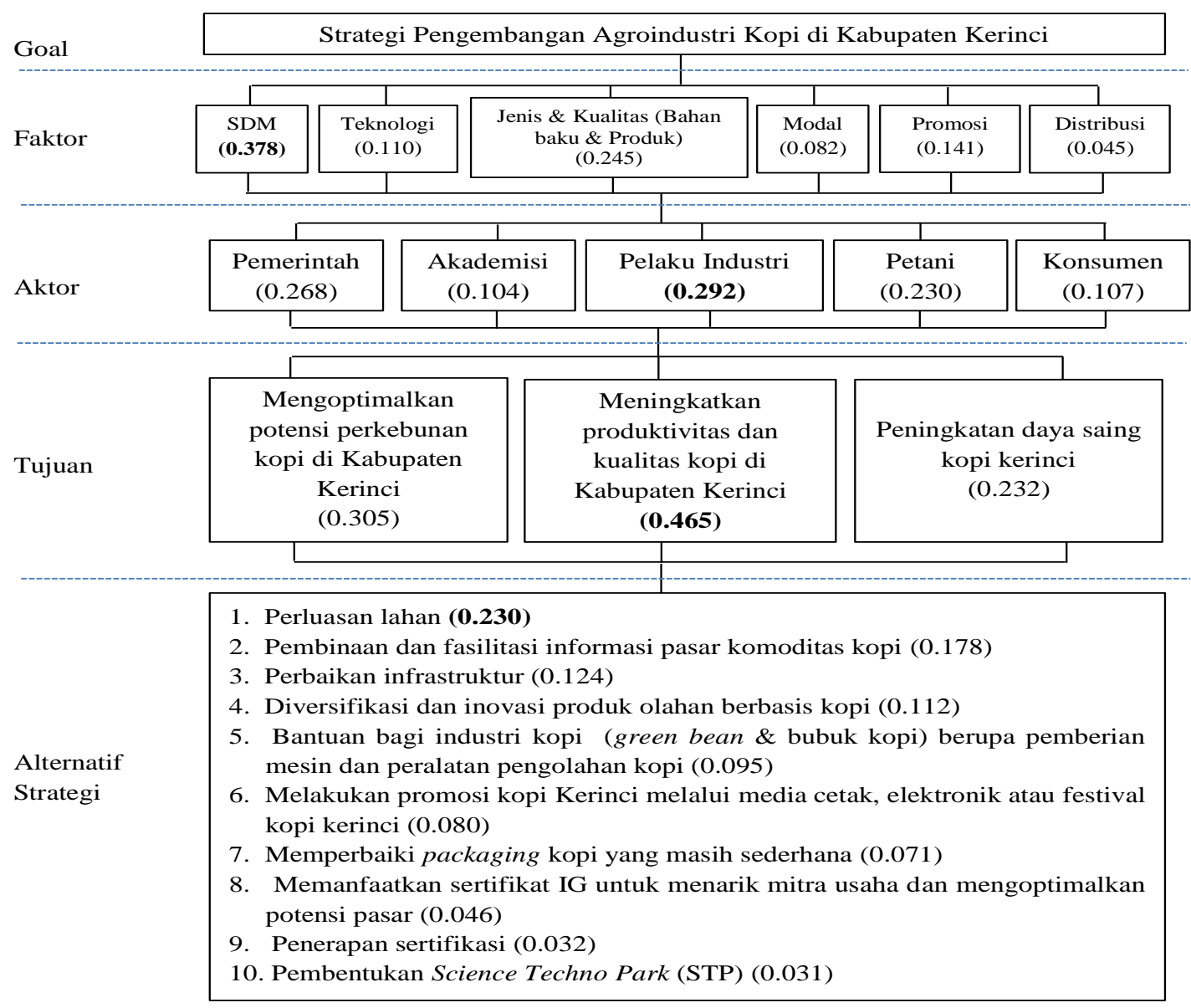

Gambar 2. Hirarki pemilihan strategi

\section{Hasil Penilaian Hirarki Level 2 (Faktor)}

Unsur faktor yang memiliki bobot tertinggi dalam strategi pengembangan agroindustri kopi di Kabupaten Kerinci adalah sumber daya manusia $(0,378)$, diikuti berturut-turut oleh jenis dan kualitas bahan baku dan produk, promosi, teknologi, modal, dan distribusi. Hasil penilaian unsur faktor disajikan pada Tabel 2.

Tabel 2. Faktor yang berpengaruh dalam strategi pengembangan agroindustri kopi di Kabupaten Kerinci

\begin{tabular}{lcc}
\hline \multicolumn{1}{c}{ Faktor } & Bobot & Prioritas \\
\hline SDM & $\mathbf{0 , 3 7 8}$ & 1 \\
Teknologi & 0,110 & 4 \\
Jenis dan Kualitas (Bahan Baku dan produk) & 0,245 & 2 \\
Modal & 0,082 & 5 \\
Promosi & 0,141 & 3 \\
Distribusi & 0,045 & 6 \\
\hline
\end{tabular}

Sumber: Data diolah (2019)

Menurut Fadhil et al. (2017) terdapat tiga elemen penting dalam mendorong proses pengembangan SDM. Pertama, kebijakan pengembangan SDM terutama dengan program-program 
pemerintah melalui dinas terkait. Kedua, dengan sistem sertifikasi produk. Ketiga, inisiasi secara swadaya dari komunitas pecinta kopi ditingkat lokal dan lembaga-lembaga penelitian, baik perguruan tinggi maupun pemerintah.

\section{Hasil Penilaian Hirarki Level 3 (Aktor)}

Unsur aktor yang memiliki bobot tertinggi dalam strategi pengembangan agroindustri kopi di Kabupaten Kerinci adalah pelaku industri $(0,292)$ diikuti berturut-turut oleh pemerintah, petani, konsumen dan akademisi. Hasil penilaian unsur aktor disajikan pada Tabel 3.

Tabel 3. Aktor yang berpengaruh dalam strategi pengembangan agroindustri kopi di Kabupaten Kerinci

\begin{tabular}{|c|c|c|}
\hline Aktor & Bobot & Prioritas \\
\hline Pemerintah & 0,268 & 2 \\
\hline Akademisi & 0,104 & 5 \\
\hline Pelaku Industri & 0,292 & 1 \\
\hline Petani & 0,230 & 3 \\
\hline Konsumen & 0,107 & 4 \\
\hline
\end{tabular}

Sumber: Data diolah (2019)

Pengembangan agroindustri kopi melibatkan beberapa aktor yaitu pemerintah, akademisi dan sektor industri. Keterlibatan aktor tersebut mengacu pada konsep triple helix, yaitu suatu konsep di negara maju yang berawal dari kebutuhan universitas untuk bekerja sama dengan industri dalam mempertajam pengetahuan dan untuk mempertahankanperkembangan yang berkelanjutan antara industri dan universitas. Peran pemerintah dalam konsep ini adalah untuk mendukung sinergi antara universitas dan industri melalui perannya sebagai pembuat keputusan dalam kaitannya mengembangkan daerah lokal (Irawati, 2006).

\section{Hasil Penilaian Hirarki Level 4 (Tujuan)}

Hasil wawancara pakar menunjukkan bahwa tujuan "Meningkatkan produktivitas dan kualitas kopi di Kabupaten Kerinci” merupakan hal terpenting dalam strategi pengembangan agroindustri kopi di Kabupaten Kerinci. Hasil penilaian tujuan disajikan pada Tabel 4.

Tabel 4. Nilai tujuan yang paling berpengaruh dalam strategi pengembangan agroindustri kopi di Kabupaten Kerinci

\begin{tabular}{lcc}
\hline \multicolumn{1}{c}{ Tujuan } & Bobot & Prioritas \\
\hline Mengoptimalkan potensi perkebunan kopi di Kabupaten Kerinci & 0,305 & 2 \\
Meningkatkan produktivitas dan kualitas kopi di Kabupaten & $\mathbf{0 , 4 6 5}$ & 1 \\
$\begin{array}{l}\text { Kerinci } \\
\text { Peningkatan daya saing kopi kerinci }\end{array}$ & 0,232 & 3 \\
\hline Sumber: Data diolah (2019) & &
\end{tabular}




\section{Alternatif Strategi Pengembangan Agroindustri di Kabupaten Kerinci}

Dalam menentukan alternatif strategi dipilih berdasarkan nilai bobot tertinggi dari masingmasing alternatif. Berdasarkan hasil analisis AHP dan gabungan peniaian pakar dengan perbandingan berpasangan didapatkan hasil prioritas alternatif strategi pengembangan agroindustri kopi yang tertinggi yaitu perluasan lahan $(0,230)$. Hasil penilaian alternatif strategi disajikan pada Tabel 5.

Tabel 5. Alternatif strategi pengembangan agroindustri kopi di Kabupaten Kerinci

\begin{tabular}{lcc}
\hline \multicolumn{1}{c}{ Alternatif Strategi } & Bobot & Prioritas \\
\hline 1. Perluasan lahan & $\mathbf{0 , 2 3 0}$ & 1 \\
2. Pembinaan dan fasilitasi informasi pasar komoditas kopi & 0,178 & 2 \\
3. Perbaikan infrastruktur & 0,124 & 3 \\
4. Diversifikasi dan inovasi produk olahan berbasis kopi & 0,112 & 4 \\
1. Bantuan bagi industri kopi (green bean \& bubuk kopi) berupa & 0,095 & 5 \\
pemberian mesin dan peralatan pengolahan kopi & \\
6. Melakukan promosi kopi Kerinci melalui media cetak, & 0,080 & 6 \\
elektronik ataupun festival kopi kerinci & 0,071 & 7 \\
7. Memperbaiki packaging kopi yang masih sederhana & 0,046 & 8 \\
8. Memanfaatkan sertifikat IG untuk menarik mitra usaha dan & 0,032 & 9 \\
mengoptimalkan potensi pasar & 0,031 & 10 \\
9. Penerapan sertifikasi &
\end{tabular}
Sumber : Data diolah (2019)

Penilaian hirarki alternatif strategi untuk pengembangan agroindustri kopi di Kabupaten Kerinci diperoleh dari sudut pandang para pakar yaitu pemerintah, akademisi, pelaku industri dan konsumen. Berdasarkan analisis AHP prioritas strategi yang dapat digunakan untuk pengembangan agroindustri kopi di Kabupaten Kerinci berturut-turut berdasarkan nilai tertinggi yaitu Perluasan lahan kopi $(0,230)$, pembinaan dan fasilitasi informasi pasar komoditas kopi $(0,178)$, perbaikan infrastruktur $(0,124)$, diversifikasi dan inovasi produk olahan berbasis kopi $(0,112)$, Bantuan bagi industri kopi (green bean \& bubuk kopi) berupa pemberian mesin dan peralatan pengolahan kopi $(0,095)$, melakukan promosi kopi Kerinci melalui media cetak, elektronik ataupun festival kopi kerinci (0,080), memperbaiki packaging kopi yang masih sederhana $(0,071)$, memanfaatkan sertifikat IG untuk menarik mitra usaha dan mengoptimalkan potensi pasar $(0,046)$, penerapan sertifikasi (0,032), dan pembentukan Science Techno Park (STP) $(0,031)$ dengan nilai inkonsistensi keseluruhan 0,03 (dapat diterima).

\section{KESIMPULAN DAN SARAN}

\section{Kesimpulan}

Agroindustri kopi di Kabupaten Kerinci saat ini berada dalam posisi yang berpotensi bagus namun belum memaksimalkan seluruh aspek yang dimiliki. Berdasarkan hasil penelitian diperoleh 
nilai faktor internal sebesar 2,759 dan nilai faktor eksternal sebesar 2,888. Jika dipetakan pada matriks IE maka nilai tersebut berada pada sel V (lima). Strategi yang sesuai untuk pengembangan agroindustri kopi di kabupaten kerinci adalah strategi pertumbuhan (growth) dan strategi stabilitas (stability) strategi tersebut berupa penetrasi pasar dan pengembangan atau peningkatan produk. Berdasarkan analisis AHP tiga prioritas strategi utama yang dapat digunakan untuk pengembangan agroindustri kopi di Kabupaten Kerinci yaitu Perluasan lahan kopi $(0,230)$, pembinaan dan fasilitasi informasi pasar komoditas kopi $(0,178)$ dan perbaikan infrastruktur $(0,124)$ dengan nilai inkonsistensi keseluruhan 0,03 (dapat diterima).

\section{Saran}

Kerjasama semua stakeholder yang terkait diperlukan agar industri dapat terus tumbuh dan berkembang sehingga kegiatan agroindustri kopi dapat berjalan baik di Kabupaten Kerinci. Perlu dilakukan penelitian lebih lanjut mengenai studi kelayakan bisnis yang diteliti dari segi teknis, kelembagaan, finansial, pasar, teknologi hingga lingkungan dan sosial budaya agar pengembangan agroindustri kopi di Kabupaten Kerinci menjadi lebih komprehensif dan dapat berkelanjutan.

\section{DAFTAR PUSTAKA}

Abdullah, N. (2017). Strategi Pengembangan Kopi Secara Optimal untuk Meningkatkan Nilai Tambah Ekonomi Wilayah di Kabupaten Mamasa Sulawesi Barat. Unpublished undergraduate thesis, Institut Pertanian Bogor, Bogor.

Chandra, D., Ismono, R. H., \& Kasymir, E. (2013). Prospek perdagangan kopi robusta indonesia di pasar internasional. Jurnal Ilmu-Ilmu Agribisnis, 1(1), 10-15.

David, F. R. (2009). Manajemen Strategi (Konsep). Jakarta (ID): Salemba Empat.

Dinas Perkebunan dan Peternakan. (2018). Potensi Produksi Kopi di Kabupaten Kerinci. Dinas Perkebunan dan Peternakan Kabupaten Kerinci.

Fadhil, R., Maarif, M. S., Bantacut, T., \& Hermawan, A. (2017). Model strategi pengembangan sumber daya manusia agroindustri kopi Gayo dalam menghadapi masyarakat ekonomi ASEAN. Jurnal Manajemen Teknologi, 16(2), 141-156.

Global Agricultural Information Network [GAIN]. (2019). Indonesia Coffee Annual Report. Jakarta (ID): USDA Foreign Agricultural Service.

International Coffee Organization [ICO]. (2019). Historical data total production by all exporting countries. Retrieved August 27, 2019, from http://www.ico.org/prices/po-production.pdf.

International Coffee Organization [ICO]. (2019). Supply surplus weighs on global coffee prices. Retrieved August 27, 2019, from https://icocoffeeorg.tumblr.com/search/consumption\%20coffee. 
Haggar, J., Soto, G., Casanoves, F., \& de Melo Virginio, E. (2017). Environmental-economic benefits and trade-offs on sustainably certified coffee farms. Ecological Indicators, 79, 330337.

Irawati, D. (2006). Understanding the triple helix model from the perspective of the developing country: A Demand or A Challenge for Indonesia Case Study. MPRA Paper No. 5829, posted 20 November 2007.

Mojo, D., Fischer, C., \& Degefa, T. (2016). The determinants and economic impact of membership in coffee farmer cooperatives: recent evidence from rural Ethiopia. Journal of Rural Studies, 50, 84-94.

Nalurita, S, Asmarantaka, R. W, Jahroh, S. (2014). Analisis dayasaing dan strategi pengembangan agribisnis kopi Indonesia. Jurnal Agribisnis Indonesia, 2(1), 63-74.

Rangkuti, F. (2016). Analisis SWOT: Teknik Membedah Kasus Bisnis. Jakarta (ID): PT Gramedia Pustaka Utama.

Saaty, T. L. (2001). Decision Making for Leaders. Pittsburgh (US): RWS Publication.

Sitanggang, J. T. N., \& Sembiring, S. A. (2013). Pengembangan potensi kopi sebagai komoditas unggulan kawasan agropolitan Kabupaten Dairi. Jurnal Ekonomi dan Keuangan, 1(6), 33-48.

Suandi. (2014). Kajian Prospek Penanaman Kopi Arabika di Kabupaten Kerinci. Program Pascasarjana. Universitas Jambi.

Sudjarmoko, B. (2013). Prospek pengembangan industrialisasi kopi Indonesia. SIRINOV, 1(3), 99110.

Syarif, R., \& Halid, H. (1993). Teknologi Penyimpanan Pangan. Laboratorium Rekayasa Pangan. Bogor: PAU Pangan dan Gizi, Institut Pertanian Bogor.

Tolinggi, W., \& Gubali, H. (2018). Agro Science Techno Park, Kajian Rintisan Kawasan. Edisi ke1. Gorontalo: Ideas Publishing.

Tominanto. (2012). Sistem pendukung keputusan dengan metode analytical hierarchy process (AHP) untuk menentukan prestasi kinerjadokter pada RSUD Sukoharjo. Jurnal Ilmiah Rekam Medis dan Informatika Kesehatan, 2(1), 1-5. 